\title{
A volumetric magnetic resonance imaging study in migraine
}

\author{
Laila Elmously Naguib', Ghada Saed Abdel Azim ${ }^{1 *}$ (D) and Mohammed Abdelrazek Abdellatif²
}

\begin{abstract}
Background: Although migraine phenotype has been widely described, the explanation of migraine pathophysiology still has a gap that might be partly bridged by neuroimaging investigations. The aim of the study is to assess volumetric brain changes in migraineurs compared with controls, and in episodic migraine in comparison to chronic type. Structural brain changes in migraineurs (with and without aura) were assessed by an automated segmentation method (Free Surfer). T1-weighted MRIs of 25 migraineurs (14 diagnosed as episodic type and 11 diagnosed as chronic migraine) and 25 headache-free controls were evaluated and processed.

Results: Migraine patients had significant reduction of the volume of total brain, grey matter, brain stem, cerebellum, basal ganglia, thalamus, hippocampus and amygdala in comparison to control subjects. Patients with chronic migraine had significant reduction in volume of total brain, grey matter, cerebellum and frontal lobe thickness in comparison to those with episodic migraine.

Conclusion: Migraineurs showed volumetric brain changes mainly in areas related to central processing of pain and in areas specific for migraine (such as brain stem) when compared to healthy controls. Chronic migraineurs showed significant reduction in grey matter, in areas involved in processing of pain, cognition and multisensory integration versus patients with episodic migraine, which adds insight into the pathophysiology of migraine as a progressive disorder that may have long-term impacts on the brain as regards structure and function.
\end{abstract}

Keywords: Brain volume, Episodic migraine, Chronic migraine, Magnetic resonance imaging

\section{Background}

Migraine is reported as a widespread neurologic disorder; it is distinguished by attacks of unilateral headache of throbbing character associated with autonomic dysfunction. Nearly $33 \%$ of migraine patients have a short-lived neurological symptom, the so-called aura. It is identified by a variant called migraine with aura. [1] Traditionally migraine is reported as a disorder that has no long-term impacts on the brain. Evolving data report that migraine patients at an increased risk of developing silent brain lesions, such as white matter lesions, ischemic like lesions and volumetric changes in both grey and white matter

\footnotetext{
*Correspondence: ghada_saed2006@yahoo.com

${ }^{1}$ The Department of Neurology, Faculty of Medicine-for Girls, Al Azhar

University, Cairo, Egypt

Full list of author information is available at the end of the article
}

found on MRI. These changes are found to be increasing along with increased number of migraine attacks, which represent a form of the disorder's anatomic progression. $[2,3]$

Migraine is considered as a continuum of illness which is composed of chronic and episodic forms. The classical episodic type of the disease usually transforms into a chronic form and the reverse is also possible. Annually, it is reported $3 \%$ of patients who have an episodic migraine progress into chronic migraine.

There are many risk factors associated with transformation into chronic migraine; they are age, head injury, low level of education, obesity, high baseline attack frequency, snoring, overuse of specific categories of medications, caffeine, and stressful life events. [4]

Upon transformation into chronic type, headache attacks become frequent, being more disabling and 
being less responsive to therapy. Although it is known that chronic migraine is generally evolved from episodic form, emerging epidemiologic proof supports distinctive underlying pathophysiology of the two states of migraine. The chronic migraine pathophysiology has not been fully elucidated. However, both structural and functional abnormalities in pain processing regions, sensitization of the trigeminal system, cortical hyper-excitability and excessive release of vasoactive peptides have been given as the underlying pathological mechanisms responsible for chronic migraine. [5]

This study aims to investigate the total and segmental changes of brain volume in migraine patients in comparison to healthy controls, and in patients with episodic migraine in comparison to chronic type of migraine and correlate the results with headache duration and frequency using automated tissue segmentation technique.

\section{Methods}

This is a case-control comparative study conducted on 25 patients who complained of migraine (18 females, 7 males); their ages ranged from 18 to 40 years. All of them were recruited from neurology outpatient clinic of Al Zahraa University Hospital, Cairo, Egypt. Eighteen patients achieved the criteria of international classification of headache disorders (ICHD-3beta) [6] for migraine without aura and seven patients for migraine with aura. There was no history of chronic diseases or active systemic diseases, psychiatric disorders or any other neurological disorders rather than migraine.

According to the attack rate per month, the patients were divided into two groups: 14 patients who suffered from episodic migraine and 11 patients who suffered from chronic migraine.

Twenty-five healthy persons are randomly selected as a control group who were matched for gender and age; all of them had no history of any systemic, psychiatric or neurological disorders.

An informed written consent was taken from all patients and controls.

A form for assessment of headache has been completed by all patients which include demographic data regarding age, gender, occupation and character of migraine including headache duration and frequency of attacks, character and location of pain, associated with aura or not. Finally headache-related disability have been recorded according to Migraine Disability Assessment Scale (MIDAS). It was developed to measure migrainerelated disability in 3 domains: school/work, household work and family social or leisure activities. The score is

Table 1 Clinical data of patients group

\begin{tabular}{|c|c|c|c|}
\hline & & $n$ & $\%$ \\
\hline \multirow[t]{2}{*}{ Type of migraine } & Migraine with aura & $7 / 25$ & 28.0 \\
\hline & Migraine without aura & $18 / 25$ & 72.0 \\
\hline \multirow[t]{2}{*}{ Chronicity of migraine } & Chronic & 11 & 44 \\
\hline & Episodic & 14 & 56 \\
\hline \multirow[t]{2}{*}{ Site of migraine } & Unilateral & $16 / 25$ & 64.0 \\
\hline & Bilateral & $9 / 25$ & 36.0 \\
\hline \multirow[t]{2}{*}{ Frequency of migraine attacks/month } & Range & $1.00-12.00$ & \\
\hline & Mean \pm SD & $6.64 \pm 3.28$ & \\
\hline \multirow[t]{2}{*}{ Duration of migraine/year } & Range & $1.00-12.00$ & \\
\hline & Mean $\pm S D$ & $5.12 \pm 2.95$ & \\
\hline \multirow[t]{6}{*}{ Beck depression inventory score } & Range & $2.0-23.0$ & \\
\hline & Mean $\pm S D$ & $12.28 \pm 6.38$ & \\
\hline & Border & 4 & 16.0 \\
\hline & Mild & 7 & 28.0 \\
\hline & Moderate & 4 & 16.0 \\
\hline & Normal & 10 & 40.0 \\
\hline \multirow[t]{4}{*}{ BCAT Brief Cognitive Assessment Tool } & Range & $40.0-50.0$ & \\
\hline & Mean $\pm S D$ & $45.3 \pm 2.92$ & \\
\hline & $\mathrm{MCl}$ & 21 & 84.0 \\
\hline & Normal & 4 & 16.0 \\
\hline \multirow[t]{3}{*}{ MIDAS Migraine Disability Assessment Scale } & Mild & 8 & 16.0 \\
\hline & Moderate & 10 & 20.0 \\
\hline & Severe & 7 & 14.0 \\
\hline
\end{tabular}


Table 2 Comparison between patients and control groups as regards total brain volumetry $\left(\mathrm{mm}^{3}\right)$ and cortical thickness parameters $(\mathrm{mm})$

\begin{tabular}{|c|c|c|c|c|c|c|}
\hline & \multicolumn{2}{|c|}{ Patients group $(n=25)$} & \multicolumn{2}{|c|}{ Control group $(n=25)$} & \multicolumn{2}{|c|}{ Independent $t$-test } \\
\hline & Mean & SD & Mean & SD & $t$ & $P$-value \\
\hline Total brain volume & $1,011,334.52$ & $106,858.78$ & $1,183,762.92$ & $115,780.99$ & -5.472 & $<0.001^{* *}$ \\
\hline Cortex volume & $432,924.76$ & $48,463.31$ & $501,448.68$ & $50,811.57$ & -4.879 & $<0.001^{* *}$ \\
\hline Left cortex volume & $216,000.84$ & $23,741.19$ & $250,407.44$ & $25,410.40$ & -4.947 & $<0.001^{* *}$ \\
\hline Right cortex volume & $216,923.92$ & $24,793.39$ & $251,041.16$ & $25,522.06$ & -4.794 & $<0.001^{* *}$ \\
\hline Cerebral white matter volume & $406,659.44$ & $56,158.33$ & $480,763.64$ & $70,233.15$ & -4.120 & $<0.001^{* *}$ \\
\hline Left cerebral white matter volume & $203,287.80$ & $27,722.18$ & $241,162.76$ & $35,458.76$ & -4.207 & $<0.001^{* *}$ \\
\hline Right cerebral white matter volume & $203,371.72$ & $28,456.51$ & $239,600.92$ & $34,874.58$ & -4.024 & $<0.001^{* *}$ \\
\hline Total gray volume & $581,104.28$ & $59,970.81$ & $675,236.16$ & $60,018.95$ & -5.547 & $<0.001^{* *}$ \\
\hline Right cortical thickness & 2.47 & 0.13 & 2.47 & 0.12 & -0.003 & 0.997 \\
\hline Left cortical thickness & 2.47 & 0.12 & 2.47 & 0.14 & -0.027 & 0.979 \\
\hline
\end{tabular}

** $p$-value $<0.001$ highly significant

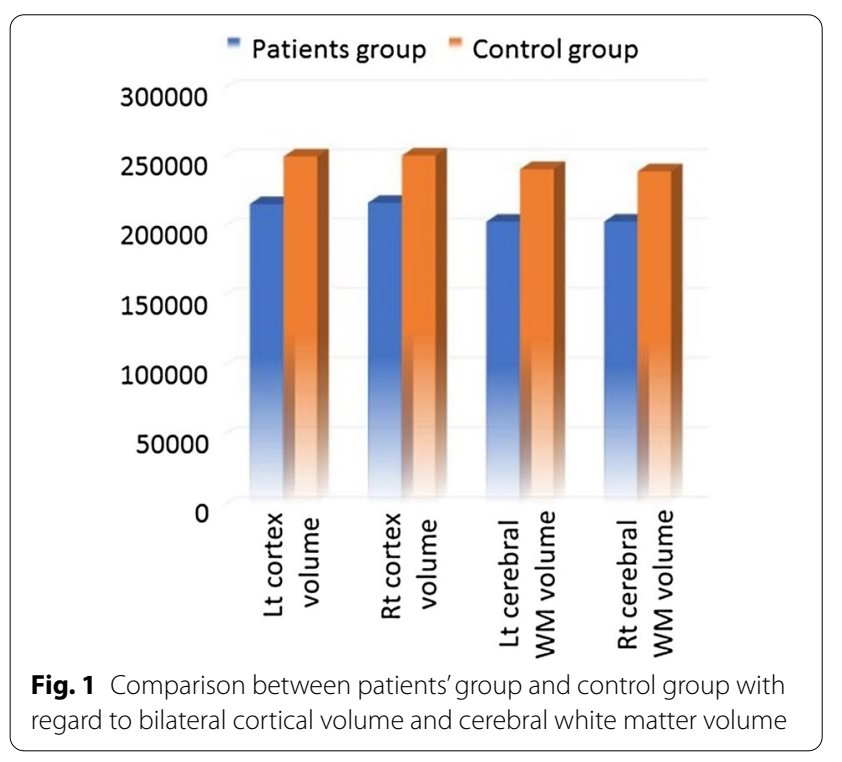

quantified by the total number of days of activity limitations due to migraine in the past 3 months [7]

The Beck Depression Inventory (BDI) was applied to all participants to assess if anyone has depression and its severity [8] and Brief Cognitive Assessment tool (BACT) were conducted to all persons in control group and patients to assess the cognitive function for everyone. It is a multi-domain cognitive instrument that assesses orientation, verbal recall, visual recognition, attention, abstraction, language, executive functions and visuo-spatial processing. [9]

As regards image acquisition and processing, highresolution MRI images using Gyro scan Integra 1.5-T MR, Philips, USA. T1-weighted axial images, T1-weighted sagittal, T2-weighted axial images and axial fluid-attenuated inversion recovery (FLAIR) images have obtained to both patients and control group. Also, T1-weighted sagittal 3D with field of view $(250 \times 250 \times 156) \mathrm{mm}$ thick, Voxel size $(11 \times 11 \times 0.6)$ $\mathrm{mm}$, TR: shortest, TE: shortest, reconstruction matrix 240, 260, sagittal slices with no gap to identify GM and WM density. MRI images were managed with Free Surfer in each individual's native space and this method involves motion correction [10] of various volumetric T1-weighted images (if other than one was obtainable), exclusion of non-brain tissue by means of a hybrid watershed/surface deformation technique [11], subdivision of subcortical white matter and deep grey matter volumetric structures containing hippocampus, amygdala, caudate, putamen, ventricles) [12, 13] intensity normalization, [14] tessellation of the grey matter white matter margin, automated topology correction $[15,16]$, and surface deformation following intensity gradients to optimally put the grey/white and grey/cerebrospinal fluid borders at the location where the greatest shift in intensity defines the transition to the other tissue class. [17-19] This method uses both intensity and continuity information from the whole three-dimensional MR volume in segmentation and deformation processes to yield representations of cortical thickness, calculated as the nearest distance from the grey/white boundary to the gray/CSF margin at each vertex on the tessellated surface. [19] The regions of interest (ROI) include cerebral and cerebellar grey and white matters, in addition to other specific structures like the basal ganglia, the limbic region (amygdala, hippocampus), brainstem and thalamus.

Statistical analysis: All data have been collected, reviewed and inserted to the Statistical Package for Social Science (IBM SPSS) version 20. It was presented as numbers and percentages for the qualitative data, 
Table 3 Comparison between patients and control groups as regards segmental brain volumetry ( $\mathrm{mm}^{3}$ ) and thickness ( $\mathrm{mm}$ ) parameters

\begin{tabular}{|c|c|c|c|c|c|c|}
\hline & \multicolumn{2}{|c|}{ Patients group $(n=25)$} & \multicolumn{2}{|c|}{ Control group $(n=25)$} & \multicolumn{2}{|c|}{ Independent $t$-test } \\
\hline & Mean & SD & Mean & SD & $t$ & $P$-value \\
\hline Brain stem volume & $18,889.66$ & 2076.85 & $21,542.80$ & 3296.72 & -3.405 & $0.001^{* *}$ \\
\hline Left cerebellar volume & $59,733.59$ & 5961.32 & $69,882.37$ & 9922.14 & -4.384 & $<0.001^{* *}$ \\
\hline Right cerebellar volume & $59,593.91$ & 5603.56 & $70,001.30$ & 9866.33 & -4.586 & $<0.001^{* *}$ \\
\hline Left caudate and putamen & 7863.20 & 999.08 & 8732.90 & 843.12 & -3.326 & $0.002^{*}$ \\
\hline Right caudate and putamen & 7948.74 & 949.98 & 8883.68 & 909.17 & -3.555 & $0.001^{* *}$ \\
\hline Left thalamus volume & 7006.94 & 821.16 & 8458.20 & 985.53 & -5.657 & $<0.001^{* *}$ \\
\hline Right thalamus volume & 6667.95 & 677.12 & 8185.10 & 1148.66 & -5.689 & $<0.001^{* *}$ \\
\hline Left hippocampus volume & 3562.09 & 416.73 & 4167.36 & 438.15 & -5.005 & $<0.001^{* *}$ \\
\hline Right hippocampus volume & 3712.36 & 424.28 & 4306.22 & 503.63 & -4.509 & $<0.001^{* *}$ \\
\hline Left amygdala volume & 1306.73 & 178.70 & 1611.09 & 199.97 & -5.675 & $<0.001^{* *}$ \\
\hline Right amygdala volume & 1435.52 & 262.29 & 1838.46 & 240.20 & -5.665 & $<0.001^{* *}$ \\
\hline Left cingulate thickness & 2.55 & 0.14 & 2.55 & 0.14 & -0.117 & 0.908 \\
\hline Right cingulate thickness & 2.53 & 0.16 & 2.58 & 0.15 & -1.093 & 0.280 \\
\hline Left frontal lobe thickness & 2.60 & 0.16 & 2.57 & 0.16 & 0.717 & 0.477 \\
\hline Right frontal lobe thickness & 2.57 & 0.16 & 2.57 & 0.15 & 0.091 & 0.928 \\
\hline Right postcentral thickness & 2.02 & 0.13 & 2.05 & 0.13 & -0.912 & 0.366 \\
\hline Left postcentral thickness & 2.03 & 0.13 & 2.08 & 0.13 & -1.331 & 0.189 \\
\hline Right superior parietal thickness & 2.12 & 0.15 & 2.17 & 0.16 & -1.107 & 0.274 \\
\hline Left superior parietal thickness & 2.15 & 0.14 & 2.17 & 0.16 & -0.445 & 0.658 \\
\hline
\end{tabular}

${ }^{*} p$-value $<0.05$ significant

** $p$-value $<0.001$ highly significant

Table 4 Comparison between chronic and episodic migraine patients as regards total brain volumetry $\left(\mathrm{mm}^{3}\right)$ and cortical thickness $(\mathrm{mm})$ parameters

\begin{tabular}{|c|c|c|c|c|c|c|}
\hline & \multicolumn{2}{|c|}{ Chronic $(n=11)$} & \multicolumn{2}{|c|}{ Episodic $(n=14)$} & \multicolumn{2}{|c|}{ Independent $t$-test } \\
\hline & Mean & SD & Mean & SD & $t$ & $p$-value \\
\hline Total brain volume & $960,994.82$ & $75,150.63$ & $1,050,887.14$ & $113,611.45$ & -2.259 & $0.034^{*}$ \\
\hline Cortex volume & $408,531.55$ & $32,686.47$ & $452,090.86$ & $51,138.20$ & -2.453 & $0.022^{*}$ \\
\hline Left cortex volume & $203,836.09$ & $15,641.45$ & $225,558.86$ & $25,075.47$ & -2.509 & $0.020^{*}$ \\
\hline Right cortex volume & $204,695.18$ & $17,166.27$ & $226,532.21$ & $26,119.34$ & -2.391 & $0.025^{*}$ \\
\hline Cerebral volume & $387,737.00$ & $41,038.96$ & $421,527.07$ & $63,132.92$ & -1.535 & 0.138 \\
\hline Left cerebral WM volume & $194,107.55$ & $20,419.03$ & $210,500.86$ & $31,156.74$ & -1.506 & 0.146 \\
\hline Right cerebral WM volume & $193,629.36$ & $20,646.01$ & $211,026.43$ & $31,994.71$ & -1.562 & 0.132 \\
\hline Total GM volume & $550,143.82$ & $37,161.32$ & $605,430.36$ & $64,257.68$ & -2.533 & $0.019^{*}$ \\
\hline Right cortical thickness & 2.44 & 0.10 & 2.49 & 0.14 & -1.159 & 0.259 \\
\hline Left cortical thickness & 2.43 & 0.09 & 2.49 & 0.14 & -1.277 & 0.214 \\
\hline
\end{tabular}

${ }^{*} p$-value $<0.05$ significant

WM white matter

GM grey matter

mean, standard deviations and ranges for the quantitative data with parametric distribution and median with inter-quartile range (IQR) for the quantitative data with non-parametric distribution. Chi-square test was used to compare between two groups with qualitative data and
Fisher exact test was used instead of the Chi-square test when the expected count in any call found less than 5 . Independent $t$-test was used to link between two clusters with quantitative data and parametric distribution and Mann-Whitney test was used in the judgment between 
Table 5 Comparison between chronic and episodic migraine patients as regards segmental brain volumetry $\left(\mathrm{mm}^{3}\right)$ and thickness $(\mathrm{mm})$ parameters

\begin{tabular}{|c|c|c|c|c|c|c|}
\hline & \multicolumn{2}{|c|}{ Chronic (No.=11) } & \multicolumn{2}{|c|}{ Episodic (No. = 14) } & \multicolumn{2}{|c|}{ Independent $t$-test } \\
\hline & Mean & SD & Mean & SD & $\bar{t}$ & $P$-value \\
\hline Brain stem volume & $18,344.76$ & 1401.35 & $19,317.80$ & 2450.27 & -1.172 & 0.253 \\
\hline Left cerebellar volume & $44,289.44$ & 2610.20 & $49,574.49$ & 5126.28 & -3.108 & $0.005^{*}$ \\
\hline Right cerebellar volume & $45,006.34$ & 2648.00 & $49,703.61$ & 4772.72 & -2.922 & $0.008^{*}$ \\
\hline Left caudate and putamen & 4586.02 & 479.66 & 4746.25 & 641.24 & -0.690 & 0.497 \\
\hline Right caudate and putamen & 4556.53 & 512.77 & 4737.00 & 558.06 & -0.831 & 0.414 \\
\hline Left thalamus volume & 6869.73 & 754.70 & 7114.75 & 882.20 & -0.733 & 0.471 \\
\hline Right-thalamus volume & 6567.45 & 598.37 & 6746.92 & 745.50 & -0.650 & 0.522 \\
\hline Left-hippocampus volume & 3525.04 & 282.80 & 3591.21 & 506.96 & -0.387 & 0.702 \\
\hline Right-hippocampus volume & 3693.85 & 316.65 & 3726.89 & 504.67 & -0.189 & 0.851 \\
\hline Left-amygdala volume & 1240.89 & 129.43 & 1358.46 & 198.79 & -1.696 & 0.103 \\
\hline Right amygdala volume & 1356.15 & 126.16 & 1497.87 & 324.42 & -1.365 & 0.185 \\
\hline Left cingulate thickness & 2.55 & 0.16 & 2.55 & 0.13 & 0.089 & 0.930 \\
\hline Right cingulate thickness & 2.52 & 0.15 & 2.54 & 0.16 & -0.293 & 0.772 \\
\hline Left frontal lobe thickness & 2.62 & 0.22 & 2.82 & 0.21 & -2.375 & $0.026^{*}$ \\
\hline Right frontal lobe thickness & 2.56 & 0.15 & 2.78 & 0.22 & -2.902 & $0.008^{*}$ \\
\hline Right post central thickness & 2.01 & 0.12 & 2.03 & 0.15 & -0.218 & 0.829 \\
\hline Left post central thickness & 2.00 & 0.11 & 2.05 & 0.13 & -1.067 & 0.297 \\
\hline Right superior parietal thickness & 2.09 & 0.13 & 2.14 & 0.16 & -0.752 & 0.460 \\
\hline Left superior parietal thickness & 2.13 & 0.09 & 2.17 & 0.17 & -0.824 & 0.418 \\
\hline
\end{tabular}

${ }^{*} p$-value $<0.05$ significant

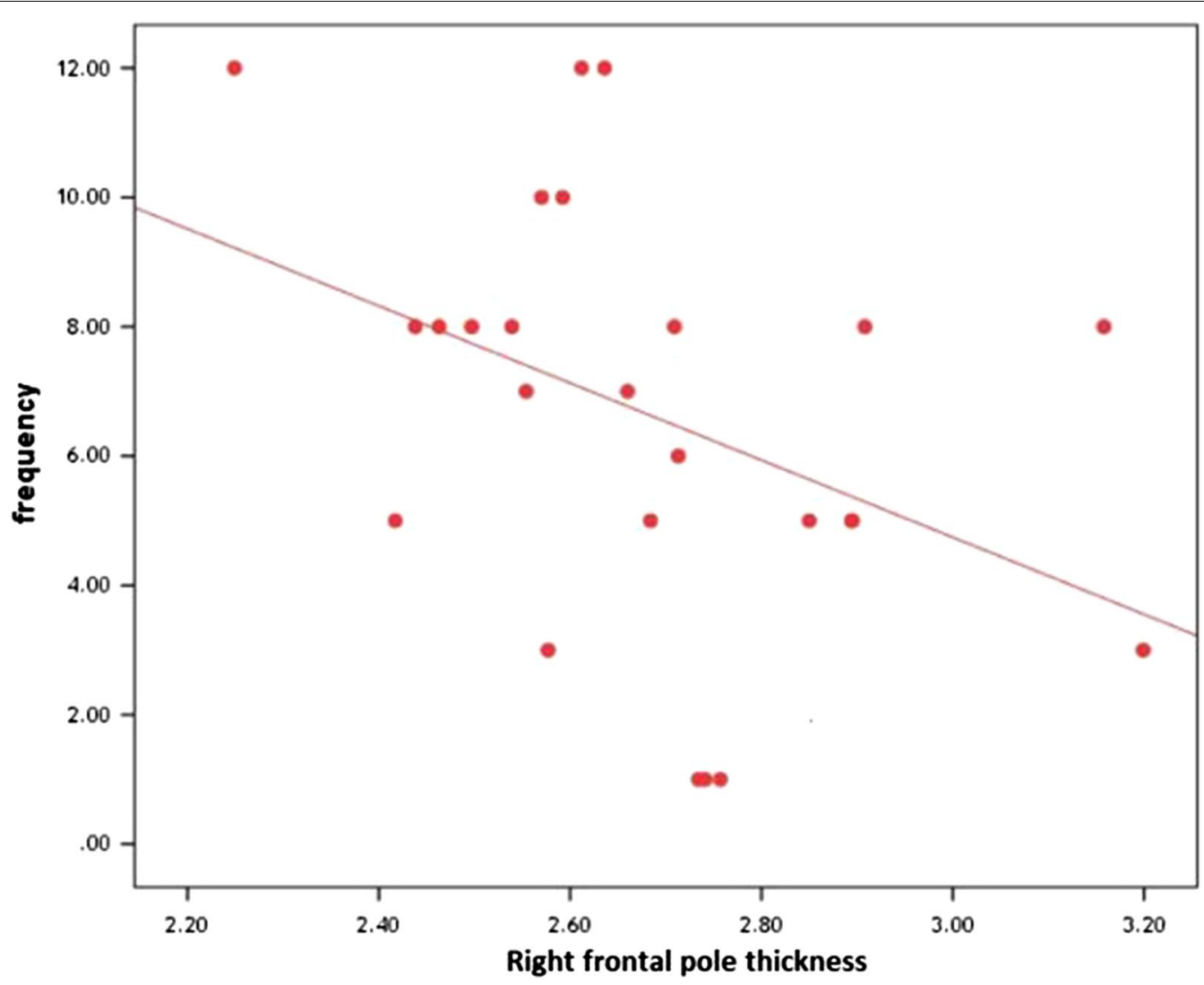

Fig. 2 Negative significant correlation between frequency of attacks and right frontal pole thickness 


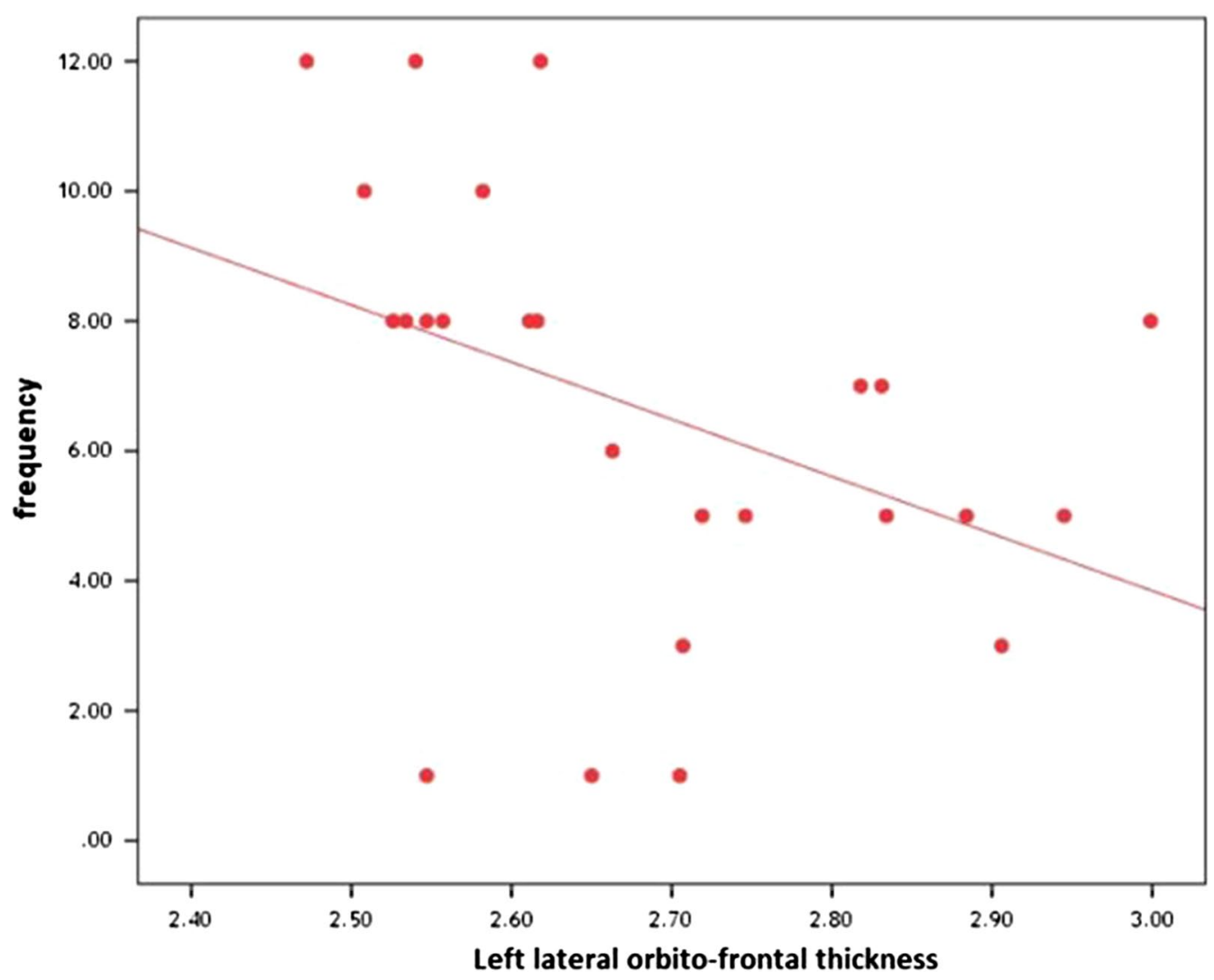

Fig. 3 Negative significant correlation between frequency of attacks and left lateral orbitofrontal thickness

two clusters with quantitative data and non-parametric distribution.

The analysis of variance (ANOVA) and Kruskal-Wallis tests have been used to compare between other clusters with quantitative data and non-parametric distribution. We used Spearman correlation coefficient to assess the significant relation between two quantitative parameters in the same group.

\section{Results}

Twenty-five patients with migraine headache (7 men $28 \%$ and 18 women $72 \%)$ with mean age $(31.00 \pm 6.93)$ as patients group and twenty-five subjects (8 men $32.00 \%$ and 17 women $68.00 \%$ ) with no symptoms of migraine as control group, mean age $(30.88 \pm 6.79)$ with age and sexmatched between two groups.

Seven patients fulfilled criteria of migraine with aura $(28.0 \%)$ with mean age $(32.57 \pm 6.80)$ and 18 patients fulfilled criteria of migraine without aura $(72.0 \%)$ with mean age (30.38 \pm 7.08$)$ (Table 1$)$.

The patients group was divided into another two subgroups: 14 patients diagnosed as episodic migraine (56\%) with mean age $(28.35 \pm 6.87)$ and 11 patients diagnosed as chronic migraine (44.0\%) with mean age (34.36 \pm 5.62$)$, with statistically significant difference between two subgroups as patients with CM were older. No one of the patients was taking medications for prophylaxis of migraine during the study.

None of the patients had severe depression or severe cognitive impairment, as shown in Table 1

As regards MRI, only 3 patients (12\%), (2 with CM and 1 with episodic migraine) had white matter hyper intensities in T2-weighted and FLAIR images.

Differences between patients and healthy controls as regards total brain volume, cortex volume, cerebral white matter volume and total grey matter volume (in $\mathrm{mm}^{3 \text { ) }}$ and cortical thickness (in $\mathrm{mm}$ ) by Free-Surfer are shown in Table 2 and Fig. 1.

As regards segmental brain volume, differences between migraine patients and healthy controls in the volume of brain stem, bilateral cerebellum, thalamusproper, caudate, putamen, hippocampus and amygdala are represented in Table 3. Also, comparison between patients and controls as regards cingulate, frontal lobe and parietal lobe thickness is shown in Table 3. 


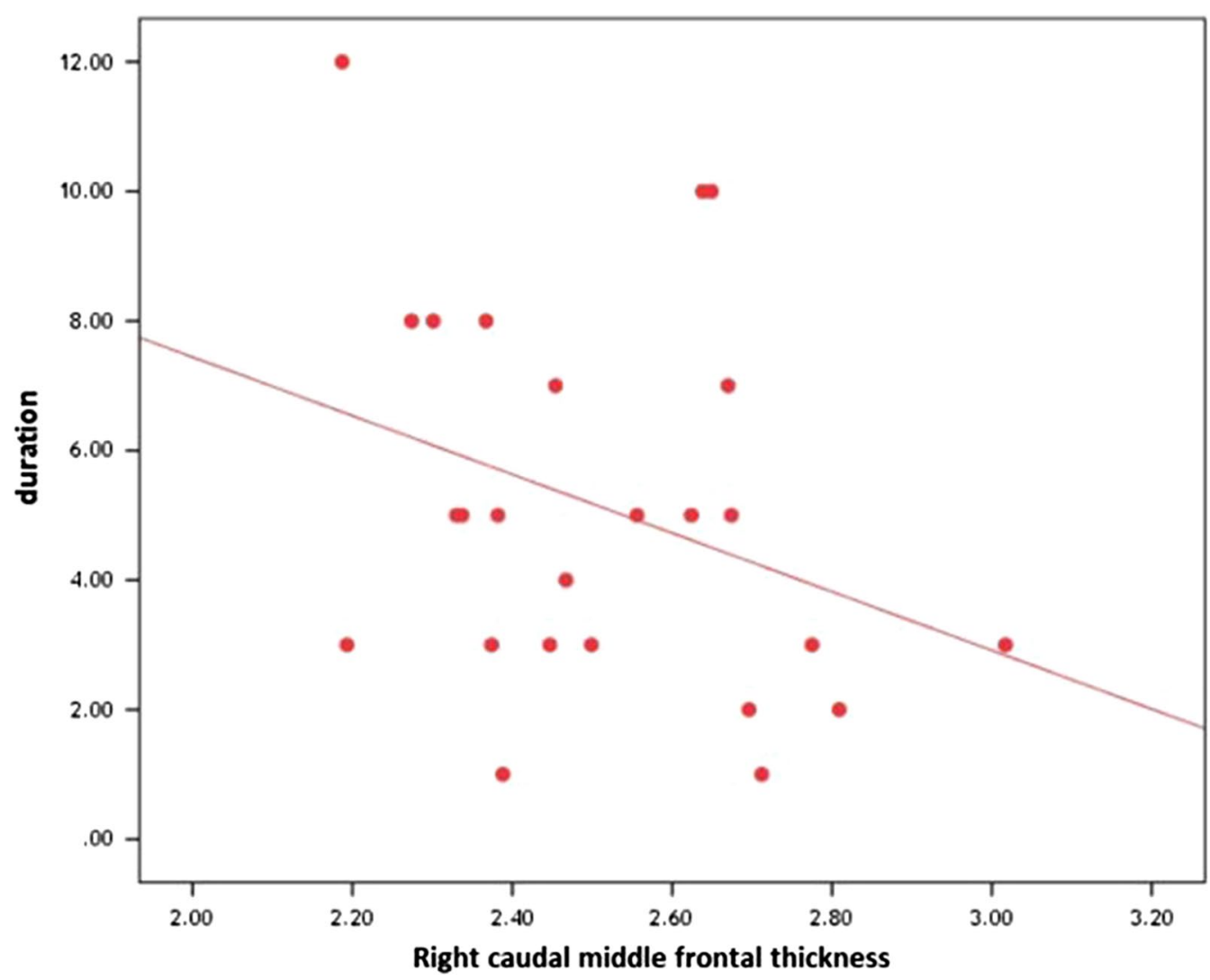

Fig. 4 Significant negative correlation between the disease duration and right caudal middle frontal thickness

In addition, differences of brain volumetric parameters (total brain volume, right and left cortex volume, and total gray matter volume) in patients with chronic migraine in comparison to those with episodic migraine, are shown in Table 4

Differences between patients with chronic migraine and patients with episodic migraine as regards cortical thickness, cerebral white matter volume, are shown in Table 4.

As regards segmental brain volumetric parameters, differences between chronic migraine patients and episodic migraine patients are shown in Table 5 .

There was no significant correlation between total brain volumetric parameters and duration of the disease or frequency of attacks in patients group.

However, correlations between frequency of attacks and both right frontal pole thickness and left lateral orbitofrontal thickness are shown in Figs. 2, 3

Correlations between the disease duration and both left medial orbitofrontal thickness and right caudal middle frontal thickness are represented in Figs. 4, 5.

Figure 6 shows abnormalities of left cortical thickness in a patient with migraine through Free-surfer software.

\section{Discussion}

Volumetric MRI remains a research tool in evaluating migraine patients. The most important finding of this study is that migraine patients had statistically significant decreased brain volume in comparison to age and sexmatched control subjects regarding total brain volume (cortex volume, cerebral white matter volume, and total grey matter volume) and segmental brain volume (the cerebellum, brainstem, thalamus-proper, caudate and putamen volume, hippocampus and amygdala volume).

In accordance with our results, Gudmundsson and colleagues, [20] found that migraineurs had reduced total brain volumetry, white matter volume, and grey matter volume compared with controls. In addition, our results are in agreement with Jia and $\mathrm{Yu}$ [21], who found in a meta-analysis of 8 clinical studies for structural changes that whole brain voxel-based morphometry (VBM) detected consistent widespread reduction in the grey matter volume (GMV) in migraine.

Proof has revealed that cerebellum is involved in emotion, cognition, and learning beside its role in motor and coordination. $[22,23]$ Furthermore, it has been demonstrated that cerebellum has a role in reaction to painful 


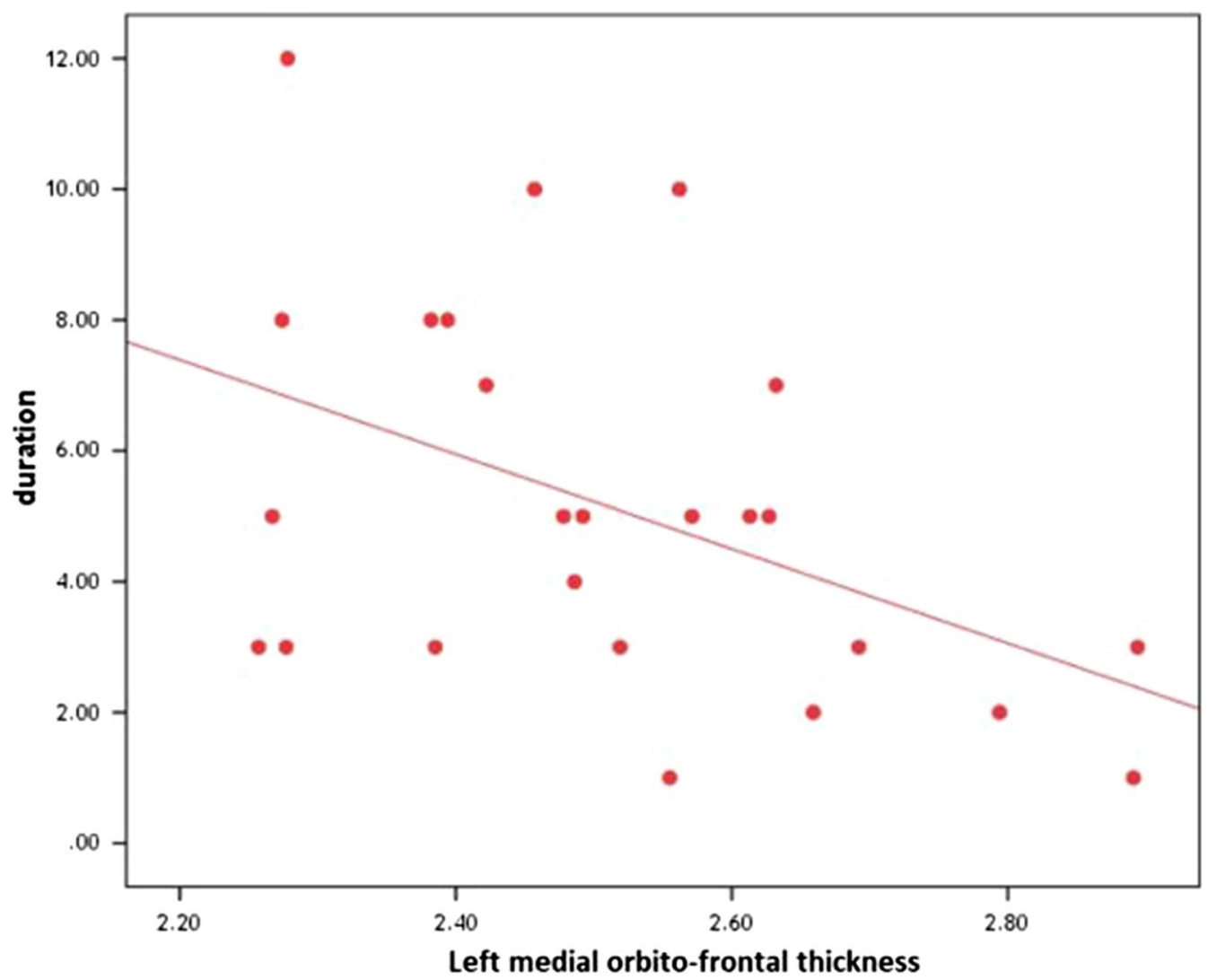

Fig. 5 Significant negative correlation between the disease duration and left medial orbitofrontal thickness

stimulations [23-26], however the precise role the cerebellum plays in processing of pain and its job as regards painful disorders is not well defined. Cerebellar activation during migraine occurs at a time of trigeminal nociception and in the course of a migraine attack. [27, 28] Moreover, further cerebellar silent ischemic lesions were present in the migraine patients. [29, 30] Some studies stated cerebellar volume alterations in migraine patients and the results were correlated with frequency of attacks. In contradiction to our study, two studies indicated gray matter volume increase of the right cerebellar hemisphere [31], which was associated with greater frailty. [32] Another two studies, in accordance with our study, revealed diminished cerebellar volume in episodic migraine patients [3] and in CM patients compared to healthy individuals. [33]

The basal ganglia are valuable grey matter structures that play a role in integrating motor, sensory, motivation, learning and cognitive functions.[34] Earlier revisions have found volume alterations, functional connectivity alterations, and iron deposits [35-37] in the basal ganglia of migraine patients. Our study demonstrated decreased volume of caudate and putamen supporting the role of the basal ganglia in migraine patients as was found in previous studies. [38, 39]

Additional deep grey matter structure which is important in migraine is the thalamus, which is in charge of pain processing, regulation of sleep-wake cycle, alertness, cognitive functions, and processing of visual information. [40] The reduction in volume of thalamic nuclei [38] or thalamic microstructural alteration [41] has been reported in migraineurs in some studies and in our present study.

The trigeminal pathway is present in the brain stem. Some studies including our current study showed diminished brain stem grey matter volume in migraine patients [42] and CM patients. [33] However in comparison to our study, others demonstrated volume increase of brain stem and sub-regions in migraine with aura [43] and in medication-overuse headache.[44] In our study, There was significant reduction in the volume of both amygdala and hippocampus in migraine patients in comparison to controls. The hippocampus, as a portion of the limbic system, has well-known function in learning, memory creation, pain processing, pain-associated attention and anxiety as well as in stress reactions [45]. Many 


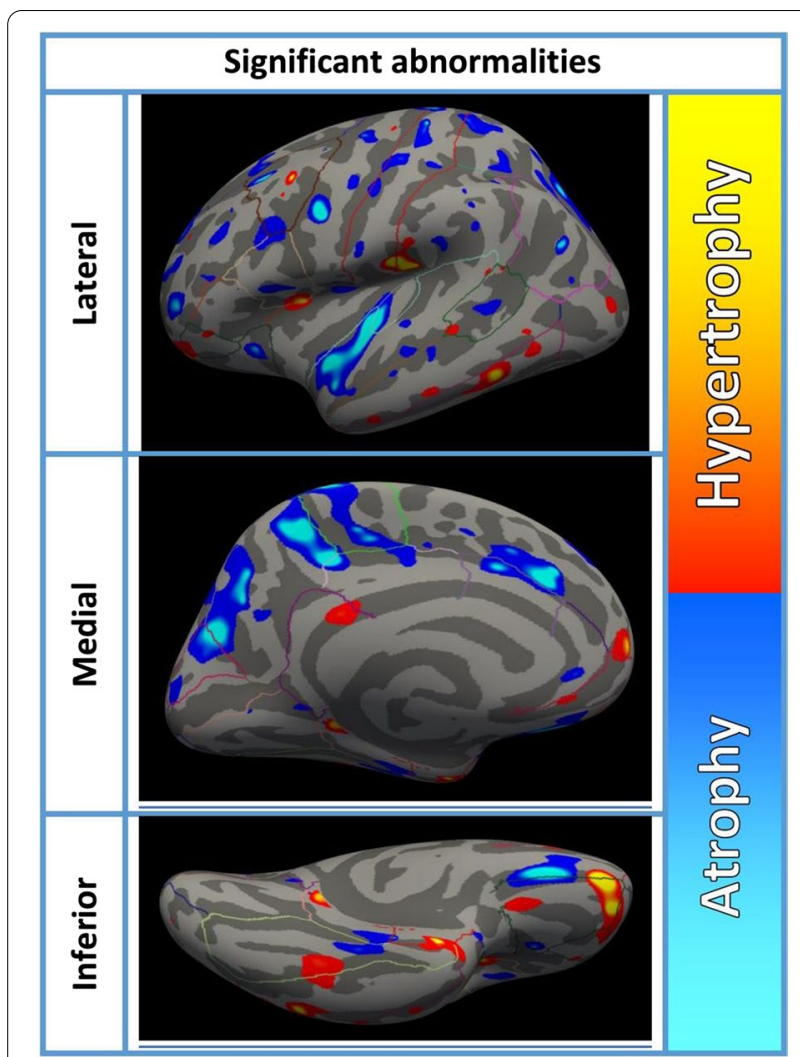

Fig. 6 Morpho-volumetric analysis through Free-surfer software showing abnormalities of left cortical thickness in a patient with migraine

previous studies explored the volume of hippocampus in migraineurs.[46-51] Hubbard and colleagues, [47] demonstrated left hippocampal enlargement in patients with migraine in comparison to healthy controls, while Chong and colleagues [46], reported the reverse. With follow-up for one year, the volume of hippocampus was reduced in patients diagnosed as episodic migraine. [51] Both increased and decreased volume of hippocampus were reported in migraine. Numerous studies' conflicting results of hippocampal volume alterations in migraine patients may be because of different sample characteristics and study designs.

The mechanism of chronicity in migraine is not completely clarified. Structural and functional imaging studies of CM have found changes in the cortex, basal ganglia, brain stem and hypothalamus, regions that are included in modulation of pain. Sometimes these alterations are related to headache rate and/or duration, but other changes may be associated with cognitive dysfunction, insomnia, mood and emotion. [52-58] These changes reflect the central nervous system plasticity that occurs in chronic migraine, but whether these alterations represent the etiology or the consequences of chronicity were not identified.

In our current research, there were valuable total brain volume reduction, cortex, white matter, cerebellum and frontal lobe thickness in CM patients in comparison to those with episodic migraine. Voxel-based morphometry revisions usually established decrease in volume or thickness of frontal cortex in chronic migraineurs.[3, $38,52,59,60]$ The prefrontal cortex has an important role in pain modulation and cognitive processing of pain through its connections with many regions of the brain, like the hippocampus, insular cortex, parietal lobe, thalamus, amygdala, basal ganglia and periaqueductal grey matter [61]. The volume reduction of the prefrontal cortex in patients with chronic migraine may be explained by impairment of function [62] and defective pain inhibition, which could stimulate migraine attacks and help migraine chronicity. [63, 64]

In this study, we found negative important association between period of the disease and both left medial orbitofrontal thickness and right caudal middle frontal thickness. Moreover, nearby was negative significant correlation between frequency of attacks and both right frontal pole thickness and left lateral orbitofrontal thickness. Our results agree with Chen and colleagues [64], who found that headache rate (headache days per month) was inversely correlated with the right frontal pole volume, right lateral orbital gyrus and left and right medial frontal lobes. However, they reported that no major association was present between other disease clinical parameters and brain volume in other regions. The way of remodeling of migraine brain is uncertain, however; it may be associated with variations as regards neurons, glial cells, number and size and their synapses, and different interstitial fluids or blood flow [65] perhaps resulting from neural moodiness, neuro-inflammation, vascular tightening or enlargement and neuronal degeneration.

The limitations of current study were, the lesser number of patients, it was a cross-sectional study and we might not identify if chronicity produced volume changes or that volume changes is the cause of chronicity. Another limitation caused by heterogenous nature of patient population, counting migraine with aura and without aura.

\section{Conclusions}

Migraineurs showed volumetric brain changes mainly in areas related to central processing of pain and in areas specific for migraine (such as brain stem) when compared to healthy controls. Chronic migraineurs showed significant reduction in grey matter, in areas involved in processing of pain, cognition and multisensory 
integration versus patients with episodic migraine, which adds insight into the pathophysiology of migraine as a progressive disorder that may have long-term impacts on the brain as regards structure and function.

\begin{abstract}
Abbreviations
MRI: Magnetic resonance imaging.; ICHD-3beta: International Classification of Headache Disorders-3beta; MIDAS: Migraine Disability Assessment Scale; BDI: The Beck Depression Inventory; BACT: Brief Cognitive Assessment tool; CSF: Cerebrospinal fluid; ROI: Regions of interest; CM: Chronic migraine; EM: Episodic migraine; WM: White matter; GM: Grey matter; VBM: Voxel-based morphometry; GMV: Grey matter volume.
\end{abstract}

\section{Acknowledgements}

We thank all the participants and the technical workers for their help and support though out the study.

\section{Authors' contributions}

LE and MA designed the research study. MA and GS performed the research. MA provided help and advice on the imaging protocol. GS, LE and MA analyzed the data. LE, GS wrote the manuscript. All authors contributed to editorial changes in the manuscript. All authors read and approved the final manuscript.

\section{Funding}

The authors did not receive any funding for this research.

\section{Availability of data and materials}

The datasets used during the current study are available from the corresponding author on reasonable request.

\section{Declarations}

\section{Ethics approval and consent to participate}

All procedures performed in the study were in accordance with the ethical standards of The Research Ethics Committee of Faculty of Medicine, for girls, Cairo, Al Azhar University (FMG-IRB) and with the 1964 Helsinki declaration and its later amendments or comparable ethical standards. We obtained approval from research ethics committee, but the number is not available. Written informed consent was taken from all patients and controls.

\section{Consent for publication}

Not applicable.

\section{Competing interests}

None of the authors has any competing interests.

\section{Author details}

${ }^{1}$ The Department of Neurology, Faculty of Medicine-for Girls, Al Azhar University, Cairo, Egypt. ${ }^{2}$ Diagnostic Radiology Department, Faculty of Medicine-for Boys, Al Azhar University, Cairo, Egypt.

Received: 8 July 2021 Accepted: 20 August 2021

Published online: 30 August 2021

\section{References}

1. Bashir A, Lipton RB, Ashina S, Ashina M. Migraine and structural changes in the brain: a systematic review and meta-analysis. Neurology. 2013;81(14):1260-8.

2. Palm-Meinders $I H$, Koppen $\mathrm{H}$, Terwindt $\mathrm{GM}$, Launer $\amalg$, Konishi J, Moonen JM, et al. Structural brain changes in migraine. JAMA. 2012;308(18):1889-97.

3. Jin C, Yuan K, Zhao L, Zhao L, Yu D, von Deneen KM, et al. Structural and functional abnormalities in migraine patients without aura. NMR Biomed. 2013;26(1):58-64.
4. Bigal ME, Lipton RB. What predicts the change from episodic to chronic migraine? Curr Opin Neurol. 2009;22:269-76.

5. Mathew NT. Pathophysiology of chronic migraine and mode of action of preventive medications. Headache. 2011;51(Suppl 2):84-92.

6. Headache Classification Committee of the International Headache Society (IHS). The international classification of headache disorders (beta version). Cephalalgia. 2013;33(9):629-808.

7. Bagley L, Rendas-Baum R, Gregory A, Yang M, Varon S, Lee J, et al. Validating migraine specific quality of life questionnaire. Headache. 2012;52(3):409-21.

8. Beck T, Steer A, Brown K. Manual for the beck depression inventory-II. San Antonio: Psychological Corporation; 1996.

9. Mansbach W, Mac Dougall E, Rosenzweig S. The Brief Cognitive Assessment Tool (BCAT): a new test emphasizing contextual memory, executive functions, attentional capacity, and the prediction of instrumental activities of daily living. J Clin Exp Neuropsychol. 2012;34(2):183-94.

10. Reuter M, Rosas D, Fischl B. Highly accurate inverse consistent registration: a robust approach. Neuroimage. 2010;53(4):1181-96.

11. Segonne F, Dale M, Busa E, Glessner M, Salat D, Hahn K, et al. A hybrid approach to the skull stripping problem in MRI. Neuroimage. 2004;22:1060-75.

12. Fischl B, Salat D, Busa E, Albert M, Dieterich M, Haselgrove C, et al. Whole brain segmentation: automated labeling of neuroanatomical structures in the human brain. Neuron. 2002;33:341-55.

13. Fischl B, Salat D, van der Kouwe A, Makris N, Ségonne F, Quinn T, et al. Sequence-independent segmentation of magnetic resonance images. Neuroimage. 2004;23(1):S69-84

14. Sled J, Zijdenbos P, Evans C. A nonparametric method for automatic correction of intensity nonuniformity in MRI data. IEEE Trans Med Imaging. 1998;17:87-97.

15. Fischl B, Liu A, Dale M. Automated manifold surgery: constructing geometrically accurate and topologically correct models of the human cerebral cortex. IEEE Trans Med Imaging. 2001;20:70-80.

16. Segonne F, Pacheco J, Fischl B. Geometrically accurate topology-correction of cortical surfaces using nonseparating loops. IEEE Trans Med Imaging. 2007;26:518529.

17. Dale M, Fischl B, Sereno I. Cortical surface-based analysis. I. Segmentation and surface reconstruction. Neuroimage. 1999:9:179-94.

18. Dale M, Sereno I. Improved localization of cortical activity by combining EEG and MEG with MRI cortical surface reconstruction: a linear approach. J Cogn Neurosci. 1993;5:162-76.

19. Fischl B, Dale A. Measuring the thickness of the human cerebral cortex from magnetic resonance images. Proc Natl Acad Sci U S A. 2000;97:11050-5.

20. Gudmundsson S, Scher I, Sigurdsson S, Mirjam G, JeanSebastien V, Gudny E. Migraine, depression, and brain volume. The AGES-Reykjavik Study. Neurology. 2013;80(23):2138-44.

21 Jia Z, Yu S. Grey matter alterations in migraine: a systematic review and meta-analysis. Neurolmage Clin. 2017;14:130-40.

22. Timmann D, Drepper J, Frings M, Maschke M, Richter S, Gerwig M, et al. The human cerebellum contributes to motor, emotional and cognitive associative learning. A review. Cortex. 2010;46(7):845-57.

23 Moulton EA, Schmahmann JD, Becerra L, Borsook D. The cerebellum and pain: passive integrator or active participator? Brain Res Rev. 2010;65(1):14-27.

24. Bocci T, Santarcangelo E, Vannini B, Torzini A, Carli G, Ferrucci R, et al. Cerebellar direct current stimulation modulates pain perception in humans. Restor Neurol Neurosci. 2015;33(5):597-609.

25. Pereira M, Rafiq B, Chowdhury E, Babayev J, Boo H, Metwaly R, et al. Anodal cerebellar tDCS modulates lower extremity pain perception. NeuroRehabilitation. 2017:40(2):195-200.

26. Bocci T, De Carolis G, Ferrucci R, Paroli M, Mansani F, Priori A, et al. Cerebellar Transcranial direct current stimulation (ctDCS) ameliorates phantom limb pain and non-painful phantom limb sensations. Cerebellum. 2019;18(3):527-35.

27 Kros L, AnqueyraAristizábal CA, Khodakhah K. Cerebellar involvement in migraine. Cephalalgia. 2018;38(11):1782-91.

28 Mehnert J, Schulte L, Timmann D, May A. Activity and connectivity of the cerebellum in trigeminal nociception. Neuroimage. 2017;150:112-8. 
29. Koppen H, Boele H-J, Palm-Meinders IH, Koutstaal BJ, Horlings CGC, Koekkoek BK, et al. Cerebellar function and ischemic brain lesions in migraine patients from the general population. Cephalalgia. 2016;37(2):177-90.

30. Kruit MC, van Buchem MA, Hofman PA, Bakkers JT, Terwindt GM, Ferrari MD, et al. Migraine as a risk factor for subclinical brain lesions. JAMA. 2004;291(4):427-34.

31 Liu HY, Lee PL, Chou KH, Lai KL, Wang YF, Chen SP, et al. The cerebellum is associated with 2-year prognosis in patients with high-frequency migraine. J Headache Pain. 2020;21(1):29.

32. Mehnert J. May A : Functional and structural alterations in the migraine cerebellum. J Cereb Blood Flow Metab. 2017;39(4):730-9.

33. Bilgiç B, Kocaman G, Arslan B, Noyan H, Sherifov R, Alkan A, et al. Volumetric differences suggest involvement of cerebellum and brainstem in chronic migraine. Cephalalgia. 2016;36(4):301-8.

34 Kreitzer AC, Malenka RC. Striatal plasticity and basal ganglia circuit function. Neuron. 2008;60:543-54.

35. Kruit MC, Launer LJ, Overbosch J, van Buchem MA, Ferrari MD. Iron accumulation in deep brain nuclei in migraine: a population-based magnetic resonance imaging study. Cephalalgia. 2009;29:351-9.

36. Yuan K, Zhao L, Cheng P, Yu D, Zhao L, Dong T, et al. Altered structure and resting-state functional connectivity of the basal ganglia in migraine patients without aura. J Pain. 2013;14:836-44.

37. Rocca MA, Messina R, Colombo B, Falini A, Comi G, Filippi M. Structural brain MRI abnormalities in pediatric patients with migraine. J Neurol. 2014;261:350-7

38. Magon S, May A, Stankewitz A, Goadsby PJ, Tso AR, Ashina M, et al. Morphological abnormalities of thalamic subnuclei in migraine: a multicenter MRI study at 3 Tesla. J Neurosci. 2015;35:13800-6.

39. Schmitz N, Arkink EB, Mulder M, Rubia K, Admiraal-Behloul F, Schoonman GG, et al. Frontal lobe structure and executive function in migraine patients. Neurosci Lett. 2008;440:92-6.

40 Younis S, Hougaard A, Noseda R, Ashina M. Current understanding of thalamic structure and function in migraine. Cephalalgia. 2019;39:1675-82.

41. Granziera C, Daducci A, Romascano D, Roche A, Helms G, Krueger G, et al. Structural abnormalities in the thalamus of migraineurs with aura: a multiparametric study at 3 T. Hum Brain Mapp. 2014;35:1461-8.

42. Marciszewski KK, Meylakh N, Di Pietro F, Macefield VG, Macey PM, Henderson LA. Altered brainstem anatomy in migraine. Cephalalgia. 2018;38:476-86

43. Petrusic I, Dakovic M, Zidverc-Trajkovic J.Volume alterations of brainstem subregions in migraine with aura. Neurolmage Clin. 2019;22:101714.

44. Chen ZY, Chen XY, Liu MQ, Ma L, Yu SY. Volume gain of brainstem on medication-overuse headache using voxel-based morphometry. Chin Med J (Engl). 2018;131:21582163.

45. Liu MG, Chen J. Roles of the hippocampal formation in pain information processing. Neurosci Bull. 2009;25(5):237-66.

46. Chong CD, Dumkrieger GM, Schwedt TJ. Structural co-variance patterns in migraine: a cross-sectional study exploring the role of thehippocampus. Headache. 2017;57(10):1522-31.

47 Hubbard CS, Khan SA, Keaser ML, Mathur VA, Goyal M, Seminowicz DA. Altered brain structure and function correlate with disease severity and pain catastrophizing in migraine patients. eNeuro. 2014;1(1):e20.14.

48. Liu HY, Chou KH, Lee PL, Fuh JL, Niddam DM, Lai KL, et al. Hippocampus and amygdala volume in relation to migraine frequency and prognosis. Cephalalgia. 2016:37(14):1329-36.
49. Liu J, Lan L, Mu J, Zhao L, Yuan K, Zhang Y, et al. Genetic contributionofcatechol-O-methyltransferaseinhippocampalstructural and functional changes of female migraine sufferers. Hum Brain Mapp. 2015;36(5):1782-95.

50. Maleki N, Becerra L, Brawn J, McEwen B, Burstein R, Borsook D. Common hippocampal structural and functional changes in migraine. Brain Struct Funct. 2013;218(4):903-12.

51. Liu J, Lan L, Li G, Yan X, Nan J, Xiong S, et al. Migraine-related gray matter and white matter changes at a 1-year follow-up evaluation. J Pain. 2013;14(12):1703-8

52. Coppola G, Petolicchio B, Di Renzo A, Tinelli E, Di Lorenzo C, Parisi V, et al. Cerebral gray matter volume in patients with chronic migraine: correlations with clinical features. J Headache Pain. 2017;18:115.

53. Neeb L, Bastian K, Villringer K, Israel H, Reuter U, Fiebach JB. Structural gray matter alterations in chronic migraine: implications for a progressive disease? Headache. 2017:57:400416.

54 Schulte LH, Allers A, May A. Hypothalamus as a mediator of chronic migraine: evidence from high-resolution fMRI. Neurology. 2017;88:2011-6.

55. Androulakis XM, Krebs KA, Jenkins C, Maleki N, Finkel AG, Rorden C, et al. Central executive and default mode network intranet work functional connectivity patterns in chronic migraine. J Neurol Disord. 2018;6:393.

56. Domínguez C, López A, Ramos-Cabrer P, Vieites-Prado A, Pérez-Mato M, Villalba C, et al. Iron deposition in periaqueductal gray matter as a potential biomarker for chronic migraine. Neurology. 2019;92:e1076-85.

57. Lee MJ, Park BY, Cho S, Kim ST, Park H, Chung CS. Increased connectivity of pain matrix in chronic migraine: a resting-state functional MRI study. J Headache Pain. 2019;20:29.

58. Woldeamanuel YW, DeSouza DD, Sanjanwala BM, Cowan RP. Clinical features contributing to cortical thickness changes in chronic migrainea pilot study. Headache. 2019;59:180-91.

59. Kim JH, Suh SI, Seol HY, Oh K, Seo WK, Yu SW, et al. Regional grey matter changes in patients with migraine: a voxel-based morphometry study. Cephalalgia. 2008;28:598-604

60. Valfrè W, Rainero I, Bergui M, Pinessi L. Voxel-based morphometry reveals gray matter abnormalities in migraine. Headache. 2008;48:109-17.

61. Ong WY, Stohler CS, Herr DR. Role of the prefrontal cortex in pain processing. Mol Neurobiol. 2019;56:1137-66.

62. Krummenacher P, Candia V, Folkers G, Schedlowski M, Schönbächler G. Prefrontal cortex modulates placebo analgesia. Pain. 2010;148:368-74.

63. Bräscher AK, Becker S, Hoeppli ME, Schweinhardt P. Different brain circuitries mediating controllable and uncontrollable pain. J Neurosci. 2016;36:5013-25.

64. Chen XY, Chen ZY, Dong Z, Liu MQ, Yu SY. Regional volume changes of the brain in migraine chronification. Neural Regen Res. 2020;15(9):1701-8.

65. May A. Experience-dependent structural plasticity in the adult human brain. Trends Cogn Sci. 2011;15:475-82.

\section{Publisher's Note}

Springer Nature remains neutral with regard to jurisdictional claims in published maps and institutional affiliations.

\section{Submit your manuscript to a SpringerOpen ${ }^{\circ}$ journal and benefit from:}

- Convenient online submission

- Rigorous peer review

- Open access: articles freely available online

- High visibility within the field

Retaining the copyright to your article

Submit your next manuscript at springeropen.com 